\title{
An Optimization of the New Die Design of Sheet Hydroforming by Taguchi Method
}

\author{
M. Hosseinzadeh, S. A. Zamani, A. Taheri
}

\begin{abstract}
During the last few years, several sheet hydroforming processes have been introduced. Despite the advantages of these methods, they have some limitations. Of the processes, the two main ones are the standard hydroforming and hydromechanical deep drawing. A new sheet hydroforming die set was proposed that has the advantages of both processes and eliminates their limitations. In this method, a polyurethane plate was used as a part of the die-set to control the blank holder force. This paper outlines the Taguchi optimization methodology, which is applied to optimize the effective parameters in forming cylindrical cups by the new die set of sheet hydroforming process. The process parameters evaluated in this research are polyurethane hardness, polyurethane thickness, forming pressure path and polyurethane hole diameter. The design of experiments based upon L9 orthogonal arrays by Taguchi was used and analysis of variance (ANOVA) was employed to analyze the effect of these parameters on the forming pressure. The analysis of the results showed that the optimal combination for low forming pressure is harder polyurethane, bigger diameter of polyurethane hole and thinner polyurethane. Finally, the confirmation test was derived based on the optimal combination of parameters and it was shown that the Taguchi method is suitable to examine the optimization process.
\end{abstract}

Keywords - Sheet Hydroforming, Optimization, Taguchi Method

\section{INTRODUCTION}

$I_{b}^{N}$ recent years, several sheet hydroforming methods have been introduced by researchers. Despite the advantages of these methods, they have some limitations. a new die-set of sheet hydroforming method [1] already proposed that is a combination of the standard and hydromechanical [2], [3] sheet hydroforming processes. The proposed method has the advantages of both processes and eliminates their limitations. In this method, a polyurethane plate was used as a part of the die-set to control the blank holder force. This paper outlines the Taguchi optimization methodology, which is applied to optimize the effective parameters in forming cylindrical cups by the new die set of sheet hydroforming process. The objective for this investigation is minimization of the forming pressure.

M. Hosseinzadeh. is with the Department of Mechanic, Islamic Azad University, Ayatollah Amoli Branch, Amol, Mazandaran, IRAN (phone: +98912-536-6319; e-mail: m_hoseinzadeh59@yahoo.com).

S. A. Zamani, is with the Department of Mechanic, Sama Technical and Vocational Training School, Islamic Azad University, Ayatollah Amoli Branch, Amol, Mazandaran, IRAN (phone: +98-911-325-9211; e-mail: Sali86_mk@yahoo.com).

A. Taheri, is with the Department of Mechanic, Mazandaran University of Science and Technology, Babol, Mazandaran, IRAN (phone: +98-911-1145893; e-mail: Alitasana@yahoo.com).
Taguchi's approach is totally based on statistical design of experiments [4], and this can economically satisfy the needs of problem solving and product/process design optimization [5]. By applying this technique one can significantly reduce the time required for experimental investigation, as it is effective in investigating the effects of multiple factors on performance as well as to study the influence of individual factors to determine which factor has more influence, which less [4], [5]. Taguchi creates a standard orthogonal array to accommodate this requirement.

\section{II.EXPERIMENTAL PROCEDURE AND TOOLING}

Sheet hydroforming process that is used in the current paper is a combination of standard and hydromechanical sheet hydroforming processes. The proposed technique has the advantages of the two processes but eliminates their defects. Fig. 1 provides a schematic illustration of the new tool set-up; it consists of a punch, a blank holder, a die, a pressure chamber, a polyurethane sheet, four screws, and an O-ring, which seals the liquid in the pressure chamber. As can be seen from the figure, the polyurethane diaphragm is used only on the region below the die and no diaphragm is used in the blank deformation zone. In this zone, the liquid is in direct contact with the blank. Thus, the diaphragm is prevented from any deformation and tearing, and lower pressure is required to form the workpiece.

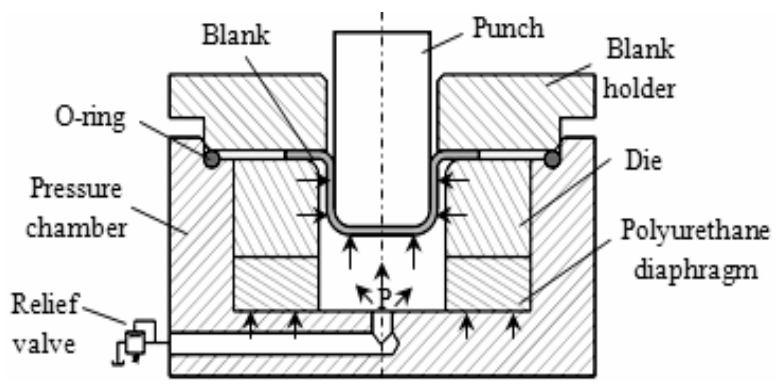

Fig. 1 Schematic illustration of the new tool set-up[1]

In contrast to conventional deep drawing, the sheet metal is not in direct contact with the die in the proposed method. Also, the blank-holding system in this method is a soft-tool system. In addition, oil pressure is applied under the polyurethane diaphragm. Thus, the blank holder force is proportional to the oil pressure. This creates a limit for the maximum forming pressure. In this way, by increasing the oil pressure, the blank holder force increases, so wrinkles can be controlled to a great extent, in comparison with 
hydromechanical and hydro-rim processes. Fig. 2 shows the picture of the new die set parts.

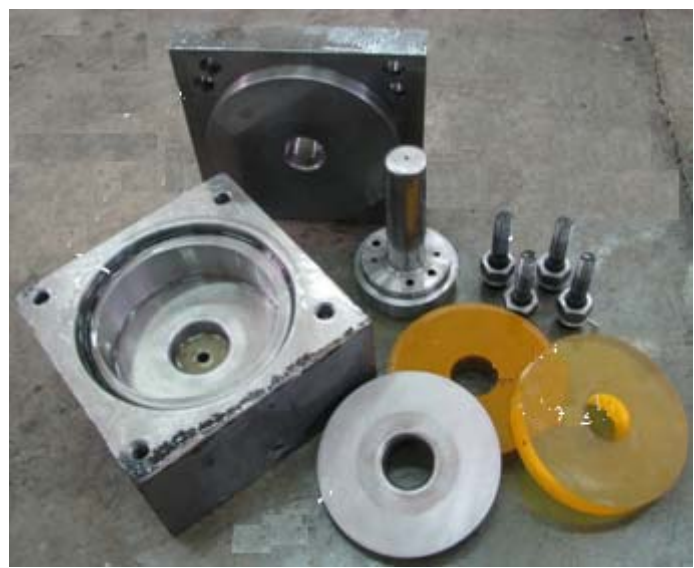

Fig. 2 Photograph of the new die set parts

The experimental tests were done by a $600 \mathrm{kN}$ DMG (Denison-Mayes Group) universal testing machine. The pressure was provided by a hydraulic unit. A control valve regulated the liquid flow to maintain the required pressure. Fig. 3 is a photograph of the manufactured die-set mounted on the test machine.

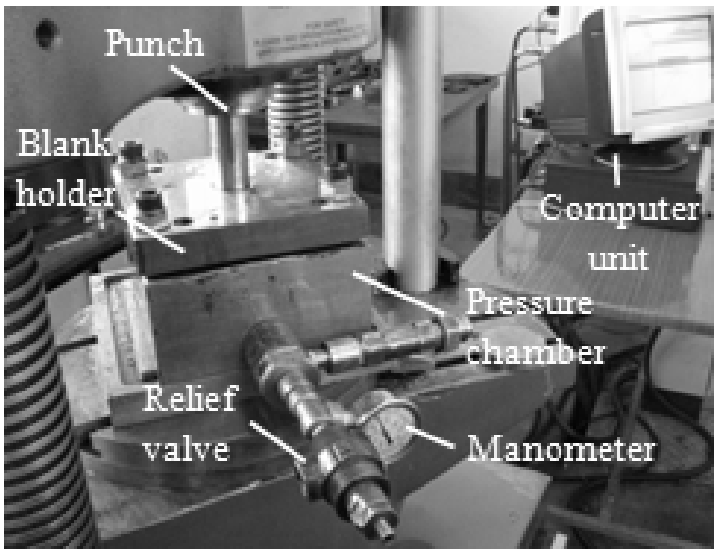

Fig. 3 Photograph of the manufactured die set mounted on the test machine

The applied material is St14 steel sheet with $1 \mathrm{~mm}$ thickness and its properties that were obtained by tensile test are shown in Table I.

TABLE I

MECHANICAL PROPERTIES OF ST14

\begin{tabular}{|c|c|c|c|c|c|}
\hline $\begin{array}{c}\text { Young's } \\
\text { modulu, } \\
\text { E } \\
(\mathrm{GPa})\end{array}$ & $\begin{array}{c}\text { Strain } \\
\text { hardening } \\
\text { exponent, } \\
n\end{array}$ & $\begin{array}{c}\text { Strength } \\
\text { coefficie, } \\
\text { K } \\
(\mathrm{MPa})\end{array}$ & $\begin{array}{c}\text { Yield } \\
\text { stress, } \\
\sigma \\
(\mathrm{MPa})\end{array}$ & $\begin{array}{l}\text { Poisson's } \\
\text { ratio }\end{array}$ & $\begin{array}{c}\text { Density, } \\
\rho \\
(\mathrm{Kg} / \mathrm{m} 3)\end{array}$ \\
\hline 210 & 0.24 & 610 & 201 & 0.3 & 7800 \\
\hline
\end{tabular}

To applying Taguchi Method, three pressure paths were used. Fig. 4 shows the first used pressure path $\left(\mathrm{P}_{1}\right)$. In this path, when the punch is in contact with the blank, the pressure increases to reach the maximum value and then remains constant. This pressure path causes plus pre-bulging with $\mathrm{h}=0$ $\mathrm{mm}$.

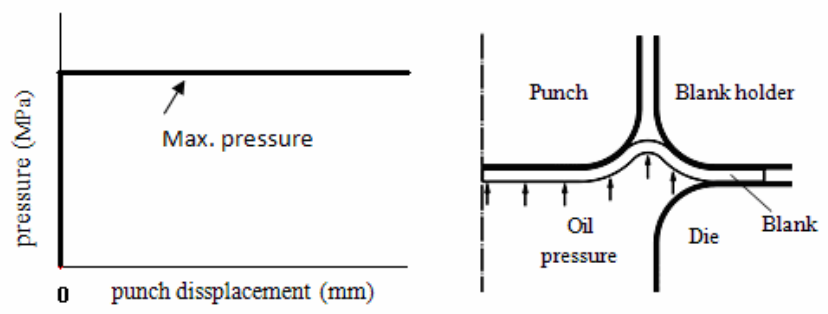

Fig. 4 The first pressure path $\left(\mathrm{P}_{1}\right)$

In the pressure path which is shown in Fig. 5, while the punch is $3 \mathrm{~mm}$ over the sheet $(\mathrm{h}=3 \mathrm{~mm})$, the pressure increases by a hydraulic pump to reach the maximum value. Then, by remaining the chamber pressure constant, the punch moves downward. This pressure path causes plus pre-bulging.

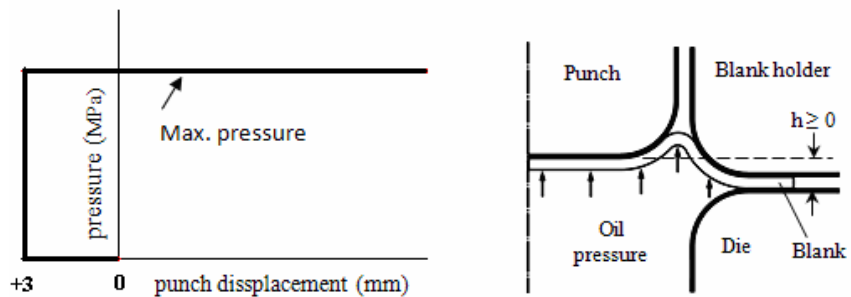

Fig. 5 The second pressure path $\left(\mathrm{P}_{2}\right)$

In the pressure path which is shown in Fig. 6, while the punch moves $3 \mathrm{~mm}$ downward $(\mathrm{h}=-3 \mathrm{~mm})$ the pressure increases. Then, by remaining the punch constant, the pressure increases by hydraulic pump to reach the maximum value. After that, while the pressure remains constant, the punch moves. This pressure path causes the minus pre-bulging.

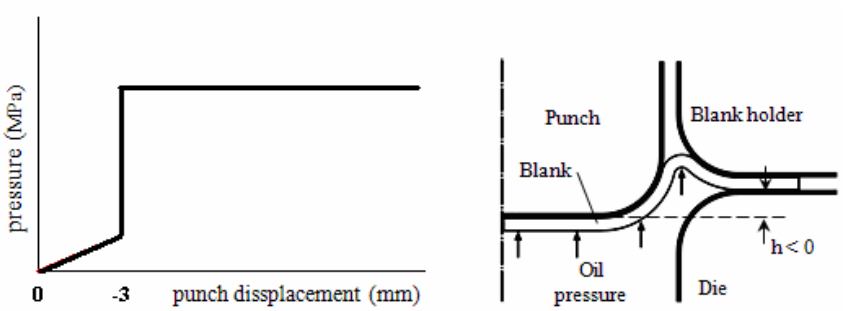

Fig. 6 The third pressure path $\left(\mathrm{P}_{3}\right)$

\section{DESIGN OF EXPERIMENTS}

The present investigation uses Taguchi method, which is a powerful design of experiments tool. This method provides a simple, efficient and systematic approach to determine optimal sheet hydroforming parameters. Conventional experimental design methods are too complex and expensive. A large number of experiments have to be carried out to study the process. Taguchi method uses an orthogonal array to study the entire process with only a small number of experiments [6]. 
Moreover, traditional experimentation involves one factor-at a time experiments, wherein one variable is changed while the rest are held constant.

It is also not possible to study all the factors involved in the process and to determine their main effects (i.e., the individual effects) in a single experiment.

The steps involved are [7]:

1. Identification of the response functions and the process parameters.

2. Determination of the number of levels for the process parameters and possible interaction between them.

3. Selection of the appropriate orthogonal array.

4. Selection of the optimum level of process parameters through ANOVA analysis.

5. Performing a confirmation experiment to verify the optimal process parameters.

The input parameters chosen for the experiments are (a) polyurethane thickness (mm), (b) forming pressure path, (c) polyurethane hole diameter $(\mathrm{mm})$, and (d) polyurethane hardness (shore A). The range and the number of levels of the design parameters are given in Table II.

TABLE II

PARAMETERS AND THEIR LEVELS

\begin{tabular}{ccccc}
\hline \hline Symbol & $\begin{array}{c}\text { parameter } \\
\text { polyurethane } \\
\text { thickness (mm) }\end{array}$ & level 1 & level 2 & level 3 \\
b & Pressure path & $\mathrm{P}_{1}$ & $\mathrm{P}_{2}$ & $\mathrm{P}_{3}$ \\
$\mathrm{c}$ & $\begin{array}{c}\text { Hole } \\
\text { diameter(mm) } \\
\text { polyurethane } \\
\text { hardness (SA) }\end{array}$ & 40 & 55 & - \\
$\mathrm{d}$ & 65 & 80 & - \\
\hline \hline
\end{tabular}

\section{DeVeloping Design Matrix}

In the present analysis, an L9 orthogonal array with three columns and nine rows is used. This array can handle three level process parameters. Therefore, only nine experiments are required to study the hydroforming process. The experimental layout for the present work using the L9 orthogonal array is shown in Table III. The coded value 1 represents the level 1,2 represents the level 2, and 3 represents the level 3.A statistical analysis of variance (ANOVA) was formed to identify the process parameters that are statistically significant. Based on ANOVA the optimal combination of the parameters is predicted.

TABLE III

EXPERIMENTAL LAY OUT USING L9 ARRAY

\begin{tabular}{cccccc}
\hline $\begin{array}{c}\text { Experimental } \\
\text { number }\end{array}$ & \multicolumn{3}{c}{ Parameter level } & $\begin{array}{c}\text { Experimental results } \\
\text { for } \mathrm{P}_{\text {min }}(\mathrm{MPa})\end{array}$ \\
1 & $\mathrm{a}$ & $\mathrm{b}$ & $\mathrm{c}$ & $\mathrm{d}$ & \\
2 & 1 & 1 & 1 & 1 & 6.9 \\
3 & 1 & 2 & 2 & 2 & 3.7 \\
4 & 1 & 3 & 1 & 1 & 6.2 \\
5 & 2 & 1 & 2 & 1 & 4.8 \\
6 & 2 & 2 & 1 & 1 & 7.5 \\
7 & 2 & 3 & 1 & 2 & 5.3 \\
8 & 3 & 1 & 1 & 2 & 6.1 \\
9 & 3 & 2 & 1 & 1 & 7.9 \\
\hline \hline
\end{tabular}

\section{V.ANALYSIS OF EXPERIMENTAL RESULTS}

The objective of experiments is to optimize the sheet hydroforming parameters to get the lowest forming pressure; the smaller is better characteristics are used. The experimental results are analyzed, to see the main effects and the difference between the main effects of level 1 and level 2 and between level 2 and level 3 of the variables on the forming pressure attained by the experiments. In the present work, only single run was performed for each of the nine experiments. As the main objective of the present research is to minimize the cost and time of the hydroforming process, the above-mentioned approach has been adopted. However, in situations where there is a feasibility to perform multiple runs for each of the experimental run provided by the design matrix, the Taguchi analysis can be performed by using either the standard deviation method or by $\mathrm{S} / \mathrm{N}$ ratio analysis.In the present analysis, considering the constraint (cost and time) mentioned above, Taguchi analysis is performed based on "average-ofresults" methodology.As it is seen in Fig. 1, in the new die set of sheet hydroforming, the oil pressure is applied under the polyurethane and it plays as a flexible blank holder. Thus, the oil pressure path, polyurethane thickness, polyurethane hardness and polyurethane hole diameter play important roles in this process.Decreasing of oil pressure leads to low blank holder force and this causes wrinkling in the flange area. A high oil pressure exerts too much blank holder force which causes tearing in the formed cup. At a constant oil pressure, by decreasing polyurethane thickness and polyurethane hardness, the maximum thinning, thin max, decreases, but the wrinkling in the flange area increases. To prevent the wrinkling, the fluid pressure should be increased. Thus, an optimized condition of internal pressure, polyurethane thickness and polyurethane hardness should be selected. Fig. 7 shows the linear graphs of the main effects of parameters and their variation between levels of the parameters on the forming pressure.

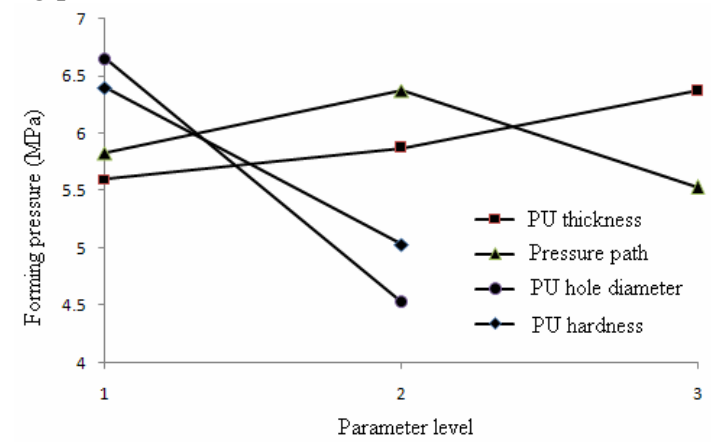

Fig. 7 Graph showing the main effect of parameters

The relative slope of the linear graphs indicates significance of the parameters. Here, the slope of the graph showing the influence of the polyurethane hole diameter is more compared to other graphs. The results of ANOVA for the response function on maximum thinning are given in Table IV. Comparison of percentage contributions of the parameters indicates that the polyurethane hole diameter is the most 
significant parameter influencing the forming pressure followed by the polyurethane hardness, polyurethane thickness and forming pressure path. This agrees with the plot in Fig. 7.

TABLE IV

ANALYSIS OF VARIANCE (ANOVA)

\begin{tabular}{cccccc}
\hline \hline $\begin{array}{c}\text { Factor } \\
\text { PU }\end{array}$ & $\begin{array}{c}\text { DOF } \\
\text { (f) }\end{array}$ & $\begin{array}{c}\text { Sum of } \\
\text { sqrs }\end{array}$ & Variance & F-ratio & percent \\
$\begin{array}{c}\text { thickness } \\
\begin{array}{c}\text { Pressure } \\
\text { path }\end{array}\end{array}$ & 2 & 0.908 & 0.454 & 12.123 & 5.664 \\
$\begin{array}{c}\text { PU hole } \\
\text { diameter } \\
\text { PU }\end{array}$ & 1 & 8.96 & 8.96 & 239.04 & 60.609 \\
$\begin{array}{c}\text { hardness } \\
\text { Other/Err } \\
\text { or } \\
\text { Total }\end{array}$ & 1 & 3.735 & 3.735 & 99.656 & 25.118 \\
\hline \hline
\end{tabular}

\section{CONFIRMATION TEST}

A confirmation experiment is needed to determine the optimum conditions and to compare the results with the expected conditions. Table $\mathrm{V}$ gives the optimum conditions for attaining minimum forming pressure. It reveals that for minimum critical forming pressure, the polyurethane thickness should be at level 1, the forming pressure path should be at level 3, the polyurethane hole diameter should be at level 2 and the polyurethane hardness should be at level 2 and the. The model predicts an optimum value of 2.865 for forming pressure. Since the optimum combination is not one of the experimental runs (according to Table III) an extra confirmation run is required.

$$
\text { TABLE V }
$$

OPTIMUM CONDITION

\begin{tabular}{ccc}
\hline \hline Factor & $\begin{array}{c}\text { Level } \\
\text { description }\end{array}$ & Level \\
PU thickness & 10 & 1 \\
Pressure path & $\mathrm{P}_{3}$ & 3 \\
PU hole & 55 & 2 \\
diameter & 80 & 2 \\
PU hardness & & \\
\hline \hline
\end{tabular}

\section{CONCLUSIONS}

The process parameters that affect the sheet hydroforming with the new die-set process have been studied using Taguchi technique. The variables affecting the forming pressure according to their relative significance are the forming pressure path, the polyurethane hardness, the polyurethane hole diameter and the polyurethane thickness, respectively. The optimum forming condition is said to be at second forming pressure path $\left(\mathrm{P}_{3}\right)$, polyurethane hardness $=80$ Shore A, polyurethane thickness $=10 \mathrm{~mm}$ and polyurethane hole diameter $=55 \mathrm{~mm}$. It has been shown that, forming parameters set at their optimum levels can ensure significant improvement in the response function.

\section{REFERENCES}

[1] M. Hosseinzade, H. Mostajeran, M. Bakhshi-Jooybari, A. Gorji, S. Nourouzi, S. J. Hosseinipour, "Novel combined standardhydromechanical sheet hydroforming process", Proc. IMechE Part B: J. Eng. Manufact., vol. 224, 2009,pp. 447-457

[2] S. H. Zhang, Z. R. Wang, Y. Xu, Z. T. Wang, L. X. Zhou, " Recent developments in sheet hydroforming technology", J. of Mat. Proc. Tech., vol.151, 2004, 237-241.

[3] S. Thiruvarudchelvan, F. W. Travis, " Hydraulic-pressure-enhanced cupdrawing processes-an appraisal", J. of Mat. Proc. Tech., vol. 140, 2003, pp. 70-75.

[4] M. Alauddin, M. A. El Baradie, M. S. J. Hashmi, "Prediction of tool life in end milling by response surface methodology", 1997. J. of Mat. Proc. Tech. vol. 71, 2003, pp.456-465.

[5] M. N. Dhavlikar, M. S. Kulkarni, V. Mariappan, " Combined Taguchi and dual response method for optimization of a centerless grinding operation" J. of Mat. Proc. Tech., vol. 132, 2003, pp. 90-104.

[6] A. Garcia-Diaz, " Principles of Experimental Design and Analysis", (1995). Chapman \& Hall, London.

[7] P. M. George, B. K. Raghunath, L. M. Manocha, A. M. Warrior, " EDM machining of carbon-carbon composite-a Taguchi Approach", J. of Mat. Proc. Tech., vol.145, 2004, pp. 66-71. 